\title{
PANDANGAN $A L$-QUR'AN TERHADAP ILMU PENGETAHUAN DAN IMPLIKASINYA DALAM PEMBELAJARAN SAINS
}

\author{
Baskoro Adhiguna ${ }^{1}$, Bramastia ${ }^{2}$ \\ ${ }^{1,2}$ Program Studi S2 Pendidikan Sains, Fakultas Keguruan dan Ilmu Pendidikan, Universitas Sebelas Maret \\ Surakarta, 57126, Indonesia \\ Email: ${ }^{1}$ baskoroadhiguna@student.uns.ac.id; ${ }^{2}$ bramastia@staff.uns.ac.id
}

Diajukan: 2 Agustus 2021; Diterima: 20 September 2021; Diterbitkan: 30 Oktober 2021

\begin{abstract}
Abstrak: Pendidikan merupakan kebutuhan bagi setiap manusia. Pendidikan dapat dikatakan sebagai suatu media bagi seseorang untuk dapat memperoleh serta mengembangkan pengetahuannya. Di dalam Al-Qur`an, ilmu adalah keistimewaan yang menjadikan manusia dipandang lebih unggul ketimbang makhluk lain guna menjalankan fungsi kekhalifahannya. Pentingnya menanamkan nilai spiritual agama dalam pembelajaran sains agar dapat meningkatkan iman dan taqwa kita kepada Tuhan yang Maha Esa dalam mengamati penciptaan alam semesta. Artikel ini menggunakan desain kajian literatur yang bertujuan untuk mendapatkan informasi dan mengintegrasikan ilmu sains dan islam. Langkah -langkah yang dilakukan diantaranya pengumpulan data pustaka, membaca dan mencatat, serta membandingkan literatur untuk kemudian diolah dan menghasilkan kesimpulan. Data yang digunakan merupakan data sekunder yang berasal dari textbook, jurnal, artikel ilmiah, literature review yang berisikan tentang konsep yang diteliti. Ilmu pengetahuan adalah keseluruhan sistem pengetahuan manusia yang telah dibakukan secara sistematis, didalam agama islam sendiri ilmu pengetahuan dikembangkan berdasarkan pada 3 pilar yaitu pilar Ontologis (yang menjadi subjek ilmu), Pilar Aksiologis (tujuan ilmu pengetahuan) dan Pilar Epistemologis (cara untuk mencapai ilmu pengetahuan tersebut). Implementasi pembelajaran sains dapat dilaksanakan dengan internalisasi nilai-nilai tauhid melalui kajian-kajian Al-Qur'an terkait dengan ilmu pengetahuan. Internalisasi nilai-nilai ketauhidan atau keyakinan terhadap agama dalam pembelajaran dapat dilaksanakan dengan 1) integrasi kurikulum, 2) integrasi pembelajaran, dan 3) integrasi sains (Islamisasi sains).
\end{abstract}

Kata Kunci : Al-Qur'an, Ilmu Pengetahuan, Implikasi, Pembelajaran Sains

Abstract: Education is a necessity for every human being. Education can be said as a medium for someone to be able to acquire and develop their knowledge. In the Qur'an, knowledge is a privilege that makes humans considered superior to other creatures in order to carry out the function of their caliphate. The importance of instilling religious spiritual values in science learning in order to increase our faith and piety to God Almighty in observing the creation of the universe. This article uses a literature review design that aims to obtain information and integrate science and Islam. The steps taken include collecting library data, reading and taking notes, and comparing the literature to then be processed and produce conclusions. The data used are secondary data derived from textbooks, journals, scientific articles, literature reviews containing the concepts studied. Science is the entire system of human knowledge that has been systematically standardized, in Islam itself science is developed based on 3 pillars, namely the Ontological pillar (which is the subject of science), the Axiological Pillar (the goal of science) and the Epistemological Pillar (the way to achieve knowledge). the). The implementation of science learning can be carried out by internalizing the values of monotheism through studies of the Qur'an related to science. Internalization of monotheistic values or belief in religion in learning can be carried out by 1) curriculum integration, 2) learning integration, and 3) science integration (Islamization of science).

Keywords: Al-Qur'an, Science, Implications, Science Learning

\section{Pendahuluan}

Pendidikan merupakan kebutuhan bagi setiap manusia. Pendidikan dapat dikatakan sebagai suatu media bagi seseorang untuk dapat memperoleh serta mengembangkan pengetahuannya, yang menyebabkan seseorang menjadi tahu apa yang sebelumnya tidak diketahui, menjadi mengerti apa yang sebelumnya tidak dimengerti dan menjadi memahami apa yang sebelumnya tidak dipahami. Pendidikan juga dapat dijadikan sebagai tolok ukur majunya suatu bangsa, yaitu dilihat dari mutu pendidikannya. Bangsa yang maju adalah bangsa yang memiliki mutu pendidikan yang tinggi, dimana bangsa 
tersebut dapat menghasilkan sumber daya manusia yang berkualitas. Pendidikan di sini tentu yang berkaitan dengan pendidikan yang bersifat formal, yang meliputi proses pembelajaran yang melibatkan guru dan siswa di dalamnya. Mutu pendidikan yang baik tentu akan menghasilkan prestasi belajar siswa yang baik pula. Kenyataan saat ini, mutu pendidikan di Indonesia belum mencapai hasil yang diharapkan, sehingga mutu pendidikan masih harus terus ditingkatkan. Peningkatan mutu pendidikan penting untuk dilakukan, karena pendidikan dianggap sebagai investasi yang paling berharga dalam bentuk peningkatan kualitas sumber daya insani untuk pembangunan suatu bangsa (Nur Raina, 2011).

Islam adalah agama yang mengajarkan umatnya untuk selalu belajar. Islam mengajarkan umatnya untuk selalu menggunakan akal pikiran yang sudah dikaruniakan Allah kepada manusia. Allah menciptakan manusia dari tidak tahu apa-apa (QS : An Nahl : 78). Islam juga agama yang memposisikan ilmu dalam posisi mulia Ahmad Satori (2003 :48). Sebagai tanda keutamaan ilmu dalam Islam adalah sifat ilmu yang menjadi salah satu sifat wajib Allah SWT (QS : Al An'am : 3). Dalam QS. al-Baqarah ayat 30-33 menunjukkan betapa pentingnya ilmu untuk manusia, bahkan manusia pertama yang Allah ciptakan, langsung mendapatkan pelajaran tentang apa-apa yang ada di surga oleh Allah. Ayat tersebut juga menjelaskan kepada kita, bahwa Islam adalah agama ilmu pengetahuan, di mana kita semua mempunyai potensi untuk mengembangkan apa yang sudah kita miliki bersama, yaitu akal pikiran kita yang merupakan anugerah Allah yang luar biasa. Ilmu yang ada membuat manusia lebih baik. Dengan ilmu manusia dapat mengarahkan perilakunya, dengan perasaannya manusia mendapatkan kesenangan. Kombinasi keduanya membuat hidup manusia lebih terarah, masuk akal dan bermanfaat. Tidak dapat disangkal bahwa ilmu sangat berperan dalam kehidupan manusia, maka bekali diri kita dengan ilmu yang bermanfaat sebanyak-banyaknya.

Kata ilmu secara etimologi berarti tahu atau pengetahuan. Kata ilmu berasal dari bahasa Arab "Alima-ya'lamu, dan science dari bahasa Latin Scio, scrie artinya to know. Sinonim yang paling akurat dalam bahasa
Yunani adalah epitisteme. Sedangkan secara terminology ilmu atau science adalah semacam pengetahuan yang mempunyai ciriciri, tanda-tanda dan syarat-syarat tertentu. Menurut ensiklopedia pengertian ilmu adalah "Ilmu pengetahuan yaitu suatu sistem dari pelbagai pengetahuan yang masing-masing mengenai suatu lapangan pengetahuan tertentu, yang disusun sedemikian rupa menurut asas-asas tertentu, sehingga menjadi kesatuan suatu sistem dari pelbagai pengetahuan yang masing-masing didapatkan sebagai hasil pemeriksaan yang dilakukan secara teliti dengan memakai metode tertentu (induksi, deduksi)". (Uyoh Sodullah , 2001).

Sedangkan istilah Sains berasal dari bahasa latin yaitu "Scientia", yang artinya pengetahuan. Pengetahuan tersebut dapat diperoleh dengan metode saintifik yaitu (1) mengidentifikasi masalah; (2) mengolah data; (3) membuat hipotesis; (4) melakukan percobaan; dan (5) membuat kesimpulan (Martin, Ralph et.al, 2005). (Patta Bundu, 2006) mendefinisikan sains secara harfiah yang berasal dari kata natural science. Natural artinya alamiah dan berhubungan dengan alam, sedangkan science artinya ilmu pengetahuan, sehingga natural science memiliki arti ilmu pengetahuan tentang alam atau yang mempelajari peristiwa-peristiwa yang terjadi di alam.

Dalam pandangan Sumantri (1982) menjelaskan bahwa tujuan sains adalah menjelaskan gejala-gejala alam dan memanipulasi faktor-faktor terkait dalam gejala tersebut untuk mengontrol dan mengarahkan proses yang terjadi. Intinya sains diciptakan untuk memenuhi kebutuhan manusia. Dari perspektif sains Islam, menurut Ghulsyani, sains islam dijadikan sebagai alat untuk mendapatkan pengetahuan tentang Allah, keridaan dan kedekatan dengan Allah. Ilmu harus dapat mengarahkan seorang Muslim dengan berbagai cara dan upaya untuk dapat dekat kepada Allah SWT. Secara spesifik, ilmu harus mampu meningkatkan pengetahuan tentang Allah SWT, membantu mengembangkan masyarakat Muslim dan merealisasikan semua tujuannya, membimbing orang lain, dan memecahkan berbagai problem masyarakat dengan demikian, seluruh ilmu (ilmu agama dan ilmu alam) merupakan alat untuk mendekatkan diri kepada Allah SWT 
dan selama ilmu memainkan peranan tersebut, maka ilmu menjadi suci. Jika ilmu tidak diarahkan kepada peranan tersebut, maka ilmu menjadi penghalang besar bagi usaha mendekatkan diri kepada Allah (Mahdi Ghulsyani, 1991).

Pentingnya menanamkan nilai spiritual agama dalam pembelajaran sains agar dapat meningkatkan iman dan taqwa kita kepada Tuhan yang Maha Esa dalam mengamati penciptaan alam semesta. Sebagaimana (Darmana, 2016) menegaskan bahwa sains sebagai sarana untuk mengembangkan potensi kognitif, sains pun dapat menumbuhkan potensi nurani (afektif). Materi sains ini akan mampu menanamkan keyakinan tentang segala sesuatu yang ada di alam. dan (Arsyad, 2016) menjelaskan bahwa dengan meyakini alam semesta yang diciptakan Allah tidaklah sia-sia, dan merupakan jalan untuk mensyukuri atas nikmat yang telah diberikan-Nya. Oleh sebab itu pentingnya artikel ini dikaji agar dapat mendeksripsikan berbagai pandangan $\mathrm{Al}$ Qur'an terhadap ilmu pengetahuan ilmiah dalam aspek pembelajaran sains Adapun kajian ini dilakukan dengan mengkaji literaturliterur terkait dengan kajian agama Islam dalam tinjauan Al-Qur'an dengan ilmu pengetahuan dalam pembelajaran sains.

\section{Metode Penelitian}

Penelitian ini menggunakan desain kajian literatur yang bertujuan untuk mendapatkan informasi dan mengintegrasikan ilmu sains dan islam. Langkah -langkah yang dilakukan diantaranya pengumpulan data pustaka, membaca dan mencatat, serta membandingkan literatur untuk kemudian diolah dan menghasilkan kesimpulan. Data yang digunakan merupakan data sekunder yang berasal dari textbook, jurnal, artikel ilmiah, literature review yang berisikan tentang konsep yang diteliti. Memulai dengan materi hasil penelitian yang secara sekuensi diperhatikan dari yang paling relevan, relevan dan cukup relevan. Membaca abstrak dari setiap penelitian terlebih dahulu untuk memberikan penilaian apakah permasalahan yang dibahas sesuai dengan yang hendak dipecahkan dalam penelitian. Mencatat bagian-bagian penting dan relevan dengan permasalahan penelitian.

\section{Hasil Penelitian dan Pembahasan}

\section{A. Pandangan Al- Qur'an Terhadap Ilmu Pengetahuan}

Dalam al-Qur`an, ilmu adalah keistimewaan yang menjadikan manusia dipandang lebih unggul ketimbang makhluk lain guna menjalankan fungsi kekhalifahannya. Ini tercermin dari kisah kejadian manusia pertama yang dijelaskan alQur`an pada Surat Al-Baqarah, 31-32:

"Dia mengajarkan kepada Adam namanama seluruhnya, kemudian mengemukakannya kepada para malaikat lalu berfirman: "Sebutkanlah kepada-Ku nama benda-benda itu jika kamu mamang benar orang-orang yang benar!". Mereka menjawab: "Maha Suci Engkau, tidak ada yang kami ketahui selain dari apa yang telah Engkau ajarkan kepada Kami; Sesungguhnya Engkaulah yang Maha Mengetahui lagi Maha Bijaksana."

Allah menampakkan tanda-tanda kebesarannya dalam pengalaman lahir batin. Hal tersebut merupakan pengembaraan manusia dalam upaya memunculkan dan memgembangkan potensi jiwa intelektual mereka yang bernuansa islami. Banyak ayatayat Al-Qur'an yang menunjukkan kebesarannya melalui kejadian-kejadian alam maupun keberagaman yang ada sehingga menggerakkan manusia untuk mencari tahu melalui pengembangan intelektual mereka. Manusia diciptakan Allah dengan potensi mencari tahu rahasia alam raya. Selain itu, Allah menciptakan alam sehingga mengantarkan manusia untuk memanfaatkan alam yang telah ditundukan Tuhan. Usaha untuk memanfaatkan alam tersebut kini kita kenal dengan teknologi. Dalam bahasa Arab, alam berasal satu akar kata dengan ilmu dan alamah (alamat, pertanda). Sehingga jagat raya dapat diartikan sebagai pertanda adanya Allah SWT Yang Maha Pencipta (Ardi Kumara, 2020).

Sebagai pertanda adanya Tuhan, jagat raya ini disebut ayat-ayat yang menjadi sumber ajaran dan pelajaran bagi manusia. Pelajaran yang dapat diambil dari pengamatan terhadap alam semesta ialah keserasian, keharmonisan, dan ketertiban (Ardi Kumara, 2020). Dalam sudut pandang ilmu pengetahuan, Al-Quran merupakan sumber ilmu yang luar biasa. Ketika Al Quran pertama 
kali diturunkan, telah menegur kekeliruan yang dilakukan manusia. Pada era Jahiliyah, berhala-berhala banyak diciptakan dan disembah sebagai tuhan. Ketika informasi yang bertentangan dengan keyakinan mereka muncul, masyarakat terkejut. Informasi tersebut mengatakan manusia diciptakan secara berproses dari segumpal darah kemudian diciptakan menjadi manusia yang kemudian lahir ke dunia. Agar manusia belajar mencari dan mengembangkan ilmu dengan cara membaca, mencoba, memperhatikan, menyelidiki dan merumuskan suatu teori, semuanya haruslah dilakukan denganberdasa pada keimanan. Dengan menyebut nama Tuhan atau mengucap bismi rabbika allazi khalaq (membaca dan belajar dengan nama Tuhanmu Yang Menciptakan). Jika ditelaah ada banyak ayat Al Quran yang berbicara mengenai alam. Kurang lebih 750 ayat $\mathrm{Al}$ Quran berisi tentang jagad raya beserta fenomenanya (Ali, 2020) dan tersurat juga dalam Al Quran bahwa alam ini diciptakan dan ditundukkan Allah untuk manusia (Yedi Purwanto, 2011).

Oleh karena itu erat kaitannya antara Islam dengan Ilmu Pengetahuan. Sebagaimana Islam hadir yang mendeklarasikan sebagai agama yang sempurna maka Islam juga memiliki sudut pandang tersendiri dalam memaknai ilmu pengetahuan. Hal ini dapat mematahkan para kaum sekularis yang menganggap ilmu pengetahuan dan agama dalam hal ini Islam tidak dapat berjalan beriringan.

\section{B. Ayat-ayat Al Qur'an yang Terkait Ilmu Pengetahuan}

\section{Penciptaan Alam Semesta}

Al-Quran menunjukkan mengenai proses yang mendasari formasi alam semesta yang menghasilkan komposisi planet yang terhampar di jagat raya ini dalam firman berikut:

"kemudian Dia menuju langit dan langit itu masih merupakan asap, lalu Dia berkata kepadanya dan kepada bumi: "Datanglah kamu keduanya menurut perintah-Ku dengan suka hati atau terpaksa." Keduanya menjawab: "Kami datang dengan suka hati." Maka Dia menjadikannya tujuh langit dalam dua masa dan Dia mewahyukan pada tiap-tiap langit urusannya. Dan Kami hiasi langit yang dekat dengan bintang-bintang yang cemerlang dan
Kami memeliharanya dengan sebaik-baiknya. Demikianlah ketentuan Yang Mahaperkasa lagi Maha Mengetahui." (QS Fushshilat [41]: 11-12).

Selain itu, ada lagi petunjuk tentang proses penciptaan alam semesta dalam firman berikut:

"Dan apakah orang-orang yang kafir tidak mengetahui bahwasanya langit dan bumi itu keduanya dahulu adalah suatu yang padu, kemudian Kami pisahkan antara keduanya. Dan dari air Kami jadikan segala sesuatu yang hidup. Maka mengapakah mereka tiada juga beriman?" (QS Al-Anbiya [21]: 30) (Afzalur, 2007).

\section{Lapisan Bumi}

"Allah-lah yang menciptakan tujuh langit dan seperti itu pula bumi. Perintah Allah berlaku padanya, agar kamu mengetahui bahwasanya Allah Maha Kuasa atas segala sesuatu, dan sesungguhnya Allah ilmu-Nya benar-benar meliputi segala sesuatu." (AtThalaq: 12).

Dari ayat ini kita bisa menyimpulkan bahwa maksud dari tujuh bumi adalah tujuh lapisan pembentuk bumi. Pada zaman modern, terungkap fakta ilmiah bahwa bumi mempunyai tujuh lapisan.

1) Atmosfer, yaitu udara yang menyelimuti planet bumi.

2) Hidrosfer, yaitu lapisan air yang berada di permukaan bumi dam meliputi perairan tawar dan asin.

3) Lapisan Sial. Lapisan ini tersusun dari silisium dan alumunium. Disebut juga kerak bumi yang bersifat bebatuan.

4) Lapisan Sima. Lapisan ini tersusun dari silisium dan magnesium.

5) Lapisan Sima berfasa besi.

6) Inti cair bumi.

7) Inti padat bumi (Nadiyah, 2013).

\section{Bulan sebagai Penunjuk Waktu bagi Manusia}

Allah berfirman, "Dialah yang menjadikan matahari bersinar dan bulan bercahaya dan ditetapkan-Nya manzilahmanzilah (tempat-tempat) bagi perjalanan bulan itu, supaya kamu mengetahui bilangan tahun dan perhitungan (waktu)." (Yunus: 5).

"Dia menyingsingkan pagi dan menjadikan malam untuk beristirahat, dan 
(menjadikan) matahari dan bulan untuk perhitungan...." (Al-An'am: 96).

"Mereka bertanya kepadamu tentang bulan sabit. Katakanlah: "Bulan sabit itu adalah tanda-tanda waktu bagi manusia..." (Al-Baqarah: 189).

"Sesungguhnya bilangan bulan pada sisi Allah adalah dua belas bulan, dalam ketetapan Allah di waktu Dia menciptakan langit dan bumi, di antaranya empat bulan haram." (AtTaubah: 36).

Ayat-ayat diatas menunjukkan bahwa Allah telah menjadikan matahari dan bulan sebagai standar perhitungan waktu hari, bulan, dan tahun bagi manusia. Dengan begitu, manusia dapat mengetahui posisi mereka, kapan dan dimana. Penelitian-penelitian astronomis telah membuktikan bahwa bulan berputar mengelilingi bola bumi sekali dalam sebulan. Ia juga berputar pada porosnya dalam masa yang sama dengan masa revolusinya tersebut (Nadiyah, 2013).

\section{Proses Terjadinya Hujan}

Dalam Surat An-Nur ayat 43, Allah SWT. Berfirman :

"Tidakkah kamu melihat bahwa Allah mengarak awan, kemudian mengumpulkan antara (bagian-bagian)nya, kemudian menjadikannya bertindih-tindih, maka kelihatanlah olehmu hujan keluar dari celahcelahnya dan Allah (juga) menurunkan (butiran-butiran) es dari langit, (yaitu) dari (gumpalan-gumpalan awan seperti) gununggunung, maka ditimpakan-Nya (butiranbutiran) es itu kepada kepada siapa yang dikehendaki-Nya dan dipalingkan-Nya dari siapa yang dikehendaki-Nya. Kilauan kilat awan itu hampir-hampir menghilangkan penglihatan" (An-Nuur : 43).

Para peneliti bidang meteorologi menyebutkan bahwa fenomena awan tebal bermula ketika angin menggiring atau mengarak kawanan awan kecil ke convergence zone (tempat berkumpul) dari awan-awan tersebut. Pengarakkan bagian-bagian ini menyebabkan bertambahnya kualitas jumlah uap air dalam perjalanannya, terutama di sekitar convergence zone. Ketika uap air sudah terlalu banyak, maka jatuhlah uap air tersebut ke permukaan bumi yang disebut hujan (Siti Lailiyah, 2018).

\section{Implementasi Ilmu Pengetahuan dalam Perspektif Al-Qur'an}

Seiring perkembangan zaman kompleksitas permasalahan turut meningkat. Karakter ilmu pengetahuan secara epistomologis semakin bergeser menjadi rasional-empiris-positivistik. Selain itu secara ontologis ilmu pengetahuan modern bersifat materilistik. Sehingga menjadikan ilmu pengetahuan menjadi tidak lagi mengenal nilia-nilai kemanusia. Pada dasarnya ilmu pengetahuan merupakan hasil karya manusia dalam upaya untuk memenuhi kebetuhunnya sekaligus menyelesaikan permasalahan yang ada secara positif. Namun kenyataanya, ilmu pengetahuan hadir seperti koin yang memiliki dua sisi yang saling bertolak belakang, disatu sisi pemahaman keilmuan tentang atom dapat dikembangkan untuk menyembuhkan penyakit, pengawetan makanan, dll yang berorientasi manfaat positif. Sedangkan disisi lain, pengembangan tentang atom dapat dijadikan senjata mematikan yang dapat membahayakan manusia, sebut saja bom atom.

Hadirnya dualitas tersebut menggerakkan sebagian saintis atau ilmuwan untuk menghadirkan kembali atau mencari paradigma baru yang dapat membangun relasi yang baik antara sains dengan agama dengan tidak menafikkan salah satunya. Hal ini muncuk Karena kegelisahan mereka dalam mengembangkan ilmu pengetahuan pada akhirnya dapat menghadirkan kebaikan maupun kemudharatan. Berdasarkan bahasan sebelumnya tantangan pun hadir dari pahampaham kaum sekularis maka upaya memunculkan paradigm ini menghadapi tantangan tersendiri selain dari permasalahan yang semakin kompleks seiring perkembangan zaman. Hal inilah yang diupayakan saintissaintis muslim yang mencoba memberikan solusi permasalahan yang ada sekaligus melakukan pembuktian wahyu Illahi untuk mematahkan paham sekularis yang saat ini berkembang (Ardi Kumara, 2020).

Islam merupakan agama pengetahuan. Sumber utama ajaran agama Islam -al-Qur`an dan al-Sunnah- menjelaskan ilmu pengetahuan dengan seluruh aspeknya. Sekaligus menganjurkan dan mendorong 
umatnya untuk menggali, mengkaji dan memformulasi ilmu pengetahuan yang ada, baik yang lafzhi maupun kauny. Adapun proses yang digunakan, berkembang sesuai dengan perkembangan zaman. Dorongan dan perintah Islam tersebut tidak ada manfaatnya bagi Allah, tapi bagi kehidupan manusia itu sendiri. Apa yang disampaikan Islam bukanlah tanpa arti dan manfaat sama sekali. Sebab tidak ada perintah dan larangan dalam Islam yang merugikan, malah menguntungkan bagi seluruh alam.

Demikian halnya dengan perintah dalam mengembangkan ilmu pengetahuan. Arti dan manfaatnya akan kembali kepada manusia itu sendiri. Manusia tidak akan mampu menguasai dunia, kalau bukan karena ilmu. Demikian pula manusia tidak akan mampu untuk mendapatkan kebahagiaan akhirat, kalau bukan karena ilmu. Dalam Islam iman, ilmu dan amal merupakan satu keterpaduan yang total. Iman menjadi dasar dalam ilmu dan amal. Demikian pula ilmu dan amal akan meningkatkan keimanan. Dengan demikian, dalam Islam tidak akan terjadi "kepribadian terpecah" (split personality). Dengan demikian barulah berlaku ganjaran Allah yang terdapat dalam surah al-Mujadilah ayat 11 yang mengangkat derajat orang yang beriman dan berilmu (Ardi Kumara, 2020).

Bentuk implementasi ilmu pengetahuan dan Islam dapat diwujudkan dengan model integrasi dan interkoneksi keilmuan merupakan sebuah upaya strategis untuk memosisikan kembali keberadaan ilmu pengetahuan dan agama dalam kedudukan yang seimbang baik dalam upaya pencarian dan pengembangan ilmu pengetahuan sekaligus pemanfaatnnya untuk ummat manusia dan alam. Munculnya konsep integrasi dan interkoneksi keilmuan tidak lain karena adanya realitas yang tidak proporsional, dimana modernisme dengan paradigma positivismenya telah meletakkan ilmu-ilmu positif lebih dominan dari pada ilmu-ilmu agama. Keadaan ini kemudian menimbulkan problem krusial bagi peradaban manusia. Oleh karena itu diperlukan upaya untuk melakukan integrasi dan interkoneksi ilmu pengetahuan dan agama merupakan sebuah keniscayaan dalam alam modern sekarang ini (Hidayatullah, 2016). Paradigma sains yang dibutuhkan masa kini supaya dapat memberikan keleluasaan untuk membangun kemaslahatan umat manusia, yaitu; paradigma sains yang meletakkan nilai rasionalisme, empirisme, positivism dan nilai intuisi (realitas spiritual) sebagai unsur epistemnya secara seimbang dan dialogis-kritis. Dengan ditambahnya unsur intuisi, maka problem ontologis dan aksiologis dari sains modern bisa dicari jalan keluarnya secara memadai (Ardi Kumara, 2020).

\section{Implikasi Al-Qur'an Terhadap Pembelajaran Sains}

Peranan integrasi Alquran dan sains dalam pendidikan modern memiliki dua misi penting, yakni pembinaan moral spiritual dan daya intelektual. Mensinergikan antara Alquran dan sains merupakan suatu keharusan, karena Alquran sendiri merupakan sumber pengetahuan yang mencakup seluruh aspek kehidupan, dengan ditambah ilmu pengetahuan teknologi yang saat ini berkembang pesat, bukan suatu hal yang mustahil jika nantinya dunia pendidikan akan mencetak generasi pemikir yang memiliki spiritualitas tinggi dibanding dengan masa lalu (Amin, 2004).

Alquran dan sains adalah dua kata yang mempunyai makna universal. Alquran ialah sebuah kitab yang menuntun kehidupan manusia. Alquran membentuk suatu aturan dan undang-undang yang berasal dari Allah SWT, Sedangkan sains adalah studi terhadap alam nyata yang tunduk kepada experimenexperimen dan persepsi persepsi manusia (Khan, 1971). Ada beberapa langkah yang dapat dijadikan acuan ke arah pengembangan model integrasi Alquran dan sains dalam pendidikan: (Ahmad, 2011)

Pertama, memetakan konsep keIlmuwan dan ke-Islaman. ilmuwan perlu diajak bertamasya bersama Alquran ke alam ilmu pengetahuan, dengan cara mengklasifikasikan sains secara sistematis ke dalam berbagai disiplin ilmu atau tema-tema yang dikehendaki. Dengan kata lain, ilmuan disarankan terlebih dahulu menjelajahi tematema sains yang ada di dalam Alquran.

Kedua, memadukan konsep keilmuan dan keislaman. Kerja ini, mengintegrasikan konsep, bukan rumus-rumus. Yaitu mencari titik kesamaan antara Alquran dan sains. Tegasnya, antara Alquran dan sains 
diintegrasikan sehingga satu sama lain saling memperkokoh dalam membuka tabir kegaiban akan realitas konkrit yang firmankan Allah SWT dalam ayat-ayat-Nya, baik yang qauliyah maupun kauniyah.

Ketiga, menjadikan Alquran sebagai pengawal dari setiap kerja sains. Alquran bukan sekedar menjadi pelengkap, tetapi sumber rujukan utama agar supaya menjadi lebih terarah dan mempunyai tujuan yang mengandungi banyak manfaat.

Sejak pertama kali diturunkan, Alquran telah mengisyaratkan pentingnya ilmu pengetahuan dan menjadikan proses pencariannya sebagai ibadah. Di samping itu, Alquran juga menegaskan bahwa satu-satunya sumber ilmu pengetahuan adalah Allah SWT. Hal ini mengindikasikan bahwa sebenarnya tidak ada pemisahan ilmu dalam pandangan Alquran (Nata, 2005). Dengan demikian, dalam pandangan Alquran dan sains merupakan dua hal yang terintegrasi. Proses pembelajaran pada hakikatnya adalah proses mengamati, menemukan, memahami, dan menghayati sunnatullah, yang berupa fenomena alamiah maupun sosial, kemudian mengaplikasikan pemahaman tersebut bagi kemaslahatan hidup manusia dan lingkungannya serta menjadikan kesadaran adanya Allah dengan sifat-sifat-Nya Yang Maha Sempurna sebagai tujuan hakiki dari kegiatan pembelajaran. Tujuan ini akan membimbing peserta belajar kepada kesadaran adanya realitas supranatural di luar realitas eksternal yang dapat ia indera. Oleh sebab itu, prinsip -prinsip dasar kegiatan ilmiah yang digariskan Alquran, harus dijadikan titik tolak dalam mempelajari subyek apapun.

Implementasi dalam pembelajaran sains, hendaknya menginternalisasikan nilai tauhid pada materi sains. (Fakhri, 2010) menjelaskan bahwa konsep ilmu pengetahuan dan teknologi dalam Al-Qur'an juga berlaku dan relevan untuk diterapkan dalam proses pembelajaran di lembaga pendidikan Islam yaitu dengan proyek integrasi dalam pendidikan. Hal tersebut dapat dijabarkan dalam tiga hal: 1) integrasi kurikulum, 2) integrasi pembelajaran, dan 3) integrasi sains (islamisasi sains) (Fakhri, 2010). Ada beberapa metode atau strategi internalisasi nilai tauhid dalam pembelajaran sains yang dapat dilakukan. Murdiono (Darmana, 2016) mengungkapkan, bahwa strategi internalisasi nilai-nilai religius dalam pembelajaran meliputi keteladanan, masalah aktual di masyarakat, penanaman nilai-nilai edukatif secara kontekstual, dan penguatan nilai moral.

Selanjutnya Darmana (2016) menjelaskan bahwa internalisasi nilai tauhid pada materi sains dapat dilakukan melalui pengungkapan nilai/hikmah/makna/hakikat dari materi sains tersebut berdasarkan sudut pandang Islam. Internalisasi nilai tauhid dalam materi sains merupakan upaya untuk mengembangkan potensi hati nurani, sehingga akan mengarahkan kepada kesadaran bahwa sains terutama hukum-hukum atau fakta-fakta, merupakan ketetapan dan kekuasaan Allah Yang Maha Kuasa, yang diciptakan dan dianugerahkan untuk kemaslahatan makhlukNya. Kesadaran ini akan mendorong dan menjadi motivasi untuk menggunakan ilmu pengetahuan pada kebaikan dan kemaslahatan umat manusia serta pada hal-hal yang diridloi oleh Allah Yang Maha Esa.

\section{Kesimpulan dan Rekomendasi}

Ilmu pengetahuan adalah keseluruhan sistem pengetahuan manusia yang telah dibakukan secara sistematis, didalam agama islam sendiri ilmu pengetahuan dikembangkan berdasarkan pada 3 pilar yaitu pilar Ontologis (yang menjadi subjek ilmu), Pilar Aksiologis (tujuan ilmu pengetahuan) dan Pilar Epistemologis (cara untuk mencapai ilmu pengetahuan tersebut). Dengan menjadikan ayat-ayat Al-Qur'an sebagai paradigma atau konsep dasar dalam keilmuan, namun tak sedikit pula manusia yang beranggapan bahwa agama dan ilmu pengetahuan adalah dua sisi yang berbeda dan tidak bisa disatukan, $\mathrm{Hal}$ ini tentu membuat dinding penghalang bagi keilmuan islam yang memiliki konsep dan paradigma yang mengarah kepada kitab AlQur'an sehingga keilmuan islam memiliki tantangan yaitu mampu menyelaraskan AlQur'an untuk menyelesaikan masalah yang berkaitan dengan ilmu pengetahuan dan juga menghadapi tantangan yang dihadirkannya.

Konsep Ilmu pengetahuan dan sains adalah sekumpulan pengetahuan yang diorganisir secara sistematis berdasarkan pengalaman dan pengamatan yang kemudian dihubungkan berdasarkan pemikiran yang cermat, teliti dan bisa dipertanggungjawabkan 
dengan berlandaskan teori dan metode yang bisa dibuktikan kebenarannya. Implementasi pembelajaran sains dapat dilaksanakan dengan internalisasi nilai-nilai tauhid melalui kajiankajian Al-Qur'an terkait dengan ilmu pengetahuan. Internalisasi nilai-nilai ketauhidan atau keyakinan terhadap agama dalam pembelajaran dapat dilaksanakan dengan 1) integrasi kurikulum, 2) integrasi pembelajaran, dan 3) integrasi sains (islamisasi sains). selain itu dapat juga diaplikasikan dengan keteladanan, masalah aktual di masyarakat, penanaman nilai-nilai edukatif secara kontekstual, dan penguatan nilai moral (Tursinawati 2020).

\section{Daftar Pustaka}

Abuddin Nata et. al., Integrasi Ilmu Agama dan Ilmu Umum (Jakarta: Raja Grafindo, 2005), h. 52 .

Afzalur Rahman, Ensiklopedia Ilmu dalam AlQur'an: RujukanTerlengkap Isyarat-Isyarat Ilmiah dalam AL-Qur'an. (Bandung: Mizan, 2007), h. 67-68.

Ahmad Barizi, Pendidikan Integratif Akar Tradisi dan Integrasi Keilmuan Pendidikan Islam, (Malang: UIN Maliki Press, 2011), h. 262.

Ali Miftakhu Rosyad and Muhammad Anas Maarif, "Paradigma Pendidikan Demokrasi dan Pendidikan Islam dalam Menghadapi Tantangan Globalisasi di Indonesia," Nazhruna: Jurnal Pendidikan Islam 3, no. 1 (2020): 75-99.

Ardi Kumara, Ayu Virnanda, Lathifah Sekar Azmi, 2020. Implementasi Ilmu Pengetahuan dalam Perspektif Al-Qur'an sebagai Upaya Menghadapi Tantangan Zaman. Jounal for Islamic Studies Al-Afkar. Vol 3 No.2

Arsyad, A. (2016). Integration Tree and the Interconnectivity of Science and Religion. Kalimah, 14(2), 115.

Bundu, Patta. (2006). Penilaian Keterampilan Proses dan Sikap Ilmiah dalam. Pembelajaran Sains di SD. Jakarta : Depdiknas.

Darmana, A. (2016). Internalisasi Nilai Tauhid Dalam Pembelajaran Sains. Jurnal Pendidikan Islam, 27(1), 66.

Fakhri, J. (2010). Sains Dan Teknologi Dalam AlQur'an Dan Implikasinya Dalam Pembelajaran. Ta'dib, 15(01), 121-142.

Ghulsyani, Mahdi, Filsafat Sains Menurut Alquran. Bandung: Mizan, 1991.
Hidayatulloh, "Relasi Ilmu Pengetahuan dan Agama", Proceeding of ICECRS 1 (2016): h. 906.

M. Amin Abdullah et al, Integrasi sains-islam (Yogyakarta: Pilar Religia, 2004), h. 18.

Martin, Ralph, Sexton, C., Franklin, T. \& Gerlovich, J. (2005). Teaching science for all children : Inquiry methods for constructing understanding.

Nadiyah Thayyarah, Buku Pintar Sains dalam AlQur'an, (Jakarta: Zaman, 2013), h.468-469.

Nur Raina Novianti, "Kontribusi Pengelolaan Laboratorium dan Motivasi Belajar Siswa terhadap Efektivitas Proses Pembelajaran," Jurnal ISSN 1412-565X Edisi Khusus, No. 1 (Agustus, 2011), h. 158

S. Jujun Suriasumntri, Filsafat Ilmu: Sebuah Pengantar Populer, Jakarta: Sinar Harapan, 1982.

Siti Lailiyah, 2018, Korelasi Al-Qur'an dengan Ilmu Pengetahuan, Prosiding Seminar Nasional Pendidikan Fisika FITK UNSIQ.

Tursinawati. 2020. Ilmu Pengetahuan dalam Pandangan Al-Qur'an dan Implikasinya dalam Pembelajaran Sains. Jurnal Pesona Dasar. PGSD Universitas Syiah Kuala, Vol.8 No.2. h. 52.

Uyoh Sodullah, Pengantar Filsafat Pendidikan, (Jakarta : Alfabeta, 2001), h. 43

Waheedudddin khan, Agama versus Sains Modern, terj. Ahmadie Thaha (Surabaya: AlIkhlas, 1971), h. 69.

Yedi Purwanto, "Islam Mengutamakan Ilmu Pengetahuan dan Teknologi", Jurnal Sosioteknologi 22, (2011): h. 1046. 